\title{
Funding Panels as Declarative Bodies: Meritocracy and Paradoxes of Decision-Making in Modern Science
}

\author{
Laura Stark
}

HCM 7: 868-886

DOI: $10.18352 / \mathrm{hcm} .593$

\begin{abstract}
In the middle of the twentieth century, bureaucratic organizations that aimed to appear democratic began using expert groups as a kind of decision-making technology. I call these groups 'declarative bodies' and funding panels are one example. Declarative bodies are distinctive types of groups because they have the power to make things in the world through declaration: their words bring new objects into being. Building on philosophy of language, this article theorizes and explains the unusual structural constraints that members of funding panels labour within by virtue of being part of a declarative body. The article argues that these constraints stem from three democratic ideals: impersonality, objectivity and truth. When put to work through declarative bodies, these democratic ideals create paradoxes that have fundamentally shaped how funding panellists labour together. Further, I argue that organizations use funding panels formally and intentionally to create the appearance that decisions were made by a disembodied actor to sanctify the legitimacy of the organizations' choices. Declarative bodies, such as funding panels, have actively altered the processes of knowledge-making, the contours of scientific communities and the products of knowledge itself. By the twenty-first century, it can be hard to imagine other acceptable methods of making decision in science, despite growing worries about the unintended, undemocratic outcomes they produce. This article encourages a critical curiosity to imagine new ways of making decisions, to declare new futures and to bring other worlds into being.
\end{abstract}


Keywords: consensus, declarative bodies, discretion, expert, J.L.

Austin, peer review, science, speech act

\section{Introduction $^{1}$}

In the middle of the twentieth century, organizations began using expert groups as a particular kind of decision-making technology. I call these groups 'declarative bodies'. Examples of declarative bodies include funding panels, ethics review boards, academic admissions committees, data and safety monitoring boards, prize committees, editorial boards and stem cell committees. ${ }^{2}$ They are 'bodies' in the sense that these groups are individual actors (even though they are constituted by multiple people). They are 'declarative' in that their decisions bring new objects into being in the world, such as the 'excellent' project, the 'ethical' study, the 'talented' researcher and the 'safe' procedure.

Although declarative bodies are not unique to the period, they became pervasive and powerful in late-modern science to an extent not previously seen. As a result, they have fundamentally affected both the process of knowledge making and, I claim, the content of late-modern scientific knowledge itself. In this article, I explain and theorize the unusual constraints that members of funding panels labour within because they are working within a type of declarative body. Often these constraints are not apparent to their members. I argue that these constraints stem from three democratic ideals that, when put into practice through declarative bodies, create paradoxes, which fundamentally shape how funding panellists labour together. Further, I argue that organizations use funding panels formally and intentionally to create the appearance of a disembodied actor to sanctify the legitimacy of the organizations' decisions.

To be clear, this article is not a criticism of people who serve on funding panels. The work is time-consuming and done with good, generous intentions. ${ }^{3}$ Indeed, I serve on funding panels myself. The aim of this article, instead, is to encourage a critical curiosity about the nature of their power and form of influence.

This article aims to prompt new questions about how funding panels work and about the precise nature of their effects. To do so, I first explain the theory behind my concept of declarative bodies. In the subsequent three sections, I identify and analyze the paradoxes contained within 
three democratic ideals that have been used to characterize declarative bodies: impersonality, objectivity and truth. Attention to funding panels as declarative bodies opens new questions for grant administrators and grant-making organizations, for researchers and for scholars in the field of history of science as well as in science and technology studies. In the conclusion, I explore why these questions are important both for intellectual and political reasons, namely, because they suggest how the world might be made differently.

\section{What Are Declarative Bodies?}

Modern organizations have, in some instances, worked to limit the power of experts, figuring them as technocratic cogs in the bureaucratic machinery or treating them as antagonists. Yet modern organizations have also extended, elaborated and legitimated bureaucratic structures that have empowered experts. Organizations have done so in order to harness the legitimacy of experts' judgement and their authority to use discretion in making decisions, which is granted so long as multiple experts weigh in on a decision.

The defining feature of declarative bodies is that they can make new things in the world through declaration: their words have the power to bring new objects into being. In speech-act theory, declarative bodies have what is called 'illocutionary force,' which means that their words are not descriptions of something that pre-existed, nor are they wishes, comments or commands. Their words are actions, and those actions have the power to produce material objects and effects in the world that did not previously exist. In the classic example from language philosopher J.L. Austin, the words of a court judge have the illocutionary force to make what had previously been two people into a third thing: a married couple. ${ }^{4}$

Importantly, individuals, institutions and the material world reorganize because of these declarative acts: they change the world, whether in ways declarative bodies intended or not. ${ }^{5}$ In the case of ethics review boards, these bodies have the illocutionary force to create an 'ethical study', not by describing the pre-existing status of a protocol when it arrives in the office, but by declaring a protocol approved, and therefore an ethical study by definition. Likewise, funding panels through the illocutionary force of their words create 'excellent studies' and 'talented 
researchers', again not by describing a pre-existing status but by creating these new entities through their decisions. Such declarations have not only verbal consequences; they also have material consequences: for example, allowing staff to be hired, money to change hands and medical interventions to be made.

Declarative bodies are intriguing and politically vexed because their purported goal is to make meritocratic decisions, and yet the way they work in practice, as well as the consequences of their decisions, are at odds with this goal. For funding organizations, the aim of making meritocratic decisions derives from three ideals of democracy: impersonality, objectivity and truth. These ideals, however, are easier to announce than to enact.

\section{Impersonality: The Expert as Neutral Authority and the Problem of Discretion}

Declarative bodies emerged within a late-modern political milieu in which impersonal decision making came to be valued in the name of democracy. ${ }^{6}$ The ideal of impersonal, democratic knowledge resonated also with a modern scientific ideal, best summed up by Thomas Nagel's praise for the 'view from nowhere'. ${ }^{7}$ This vista from 'nowhere' valued, and presumed possible, the production of knowledge that did not bear the marks of its human maker(s) and was therefore universal. Analytically, this posture regarded good decisions and true knowledge to be those that appeared detached from the specific time, location, body and political regime that yielded them, outside of the actual 'situation' of their production, in Donna Haraway's perspicuous term. ${ }^{8}$ The presumption that knowledge claims could hold universally, and that the locations, bodies and agendas involved in knowledge production are irrelevant, continues to reap ecological devastation and political dispossession across the globe. Yet this image of science as offering a "view from nowhere' was both a product and a founding myth of dominant expert communities.

In the mid-twentieth century, decision-by-experts intensified and spread into new domains. ${ }^{9}$ With the emergence and growth of the bureaucratic administrative state, national governments took on responsibilities to care for citizens that had previously been the concerns of 
families, religious communities or the private market. ${ }^{10}$ Since state administrators depended on seemingly 'democratic' decisions for their legitimacy, using scientific knowledge as the basis of decisions had strong appeal. The democratic administrative state stood in distinction to rule by fiat, monarchy, charismatic authority or other forms of personal power. Ideally, democratic decisions were to be made by no individual human authority, and thus by the ultimate secular authority: science. For organizations that purported to be democratic, including state agencies, science appealed because it seemed to give access to truth, social as well as natural, that was unmediated by humans. Scientific communities worked to make evidence seem to speak for itself and to appear not to be the product of people working in particular places with their own predilections and politics. ${ }^{11}$

Thus, bureaucratic organizations, including administrative states, turned to 'science' to make decisions in two relevant ways. First, bureaucratic administrative states directed scientists to learn the things needed for the art of war and governance: how to select soldiers, what food rations to give, when to send children to school. Governments invested financially in scientific research to learn things of practical immediate value for political order. ${ }^{12}$ Second, they used experts as seemingly neutral authorities to interpret administrative law. Why the expert? The expert was, and is, valued because of her 'trained judgment', which is the capacity to discern distinctions and see resemblances that comes only from long-term experience and apprenticeship. ${ }^{13}$

Funding panels emerged around this moment because of the political appeal of meritocracy and the increase in state funding of science. Declarative bodies expanded to domains beyond the state, such as professional associations, private philanthropies and universities, through a process that organizational sociologists call mimetic isomorphism: the process through which organizations adopt the same internal structure as dominant organizations, not because it is efficient or in line with their goals, but because, symbolically, it makes them appear more legitimate. ${ }^{14}$ As declarative bodies, funding panels became newly influential because of the logarithmic increase in public financial investment in scientific research in the mid-twentieth century.

In effect, public and private organizations turned to experts to make decisions because of their perceived political neutrality and their seeming access to the view from nowhere. At the same time, organizations 
actively empowered experts to use discretion, not to avoid it. ${ }^{15}$ The paradox of impersonality was that experts were valued both because they had the veneer of democratic disinterestedness and because they were the rare individuals qualified to judge increasingly specialized sciences. Organizations avoided pointing out that the act of empowering select individuals who were thought to possess uncommon, therefore incontestable, knowledge closely resembled the forms of governance and decision-making that 'democracy' defined itself against, namely, the rule of elite. ${ }^{16}$

For modern organizations that aspired to appear democratic, rules and standards required interpretation by experts, whether those people were expert in the field being evaluated (as is the case of funding panels, institutional review boards or publication committees) or expert in the rules themselves. One of the productive contradictions of declarative bodies has been that organizations, such as state agencies and philanthropies, have valued experts because they allow administrative rules and standards to be applied in a neutral, machine-like way, and yet organizations have turned to experts to apply rules and standards using their discretion precisely because of the perceived limitations of mechanistic decision-making.

Thus, organizations' use of experts to make decisions embed a contradiction: the notion that experts could, and indeed, ought to, apply rules and standards without bias, with the moral neutrality of an ideal machine; and yet experts had value over machines or technocrats in making decisions because of their trained judgment, empowered through discretion. ${ }^{17}$ The ideal of neutrality and the power of discretion fit awkwardly together, so declarative bodies were arranged around a very particular definition of an additional democratic ideal: objectivity.

\section{Objectivity: Empowering Groups, Requiring Consensus}

To ease this tension between two explicit and contradictory virtues attributed to the expert for making democratic decisions - political neutrality and trained judgment - declarative bodies were arranged around a specific version of objectivity. Yet this version of objectivity contained contradictions of its own. Since circa I800, scientific and political communities have tended to assume that one individual's 
perceptions cannot provide an accurate representation of the world. ${ }^{18}$ By this logic, the experiences or sensibilities of one person - even an expert - were unreliable because of the limits of human senses and tricks of the mind. Subjective perceptions came to be seen as untrustworthy. As a result, the methods, instruments, spaces and vocabularies that many knowledge-making communities developed in the modern period were directed towards creating the appearance that knowledge simply appeared in the world, untouched by human hands and minds.

Declarative bodies aimed to manage, on the one hand, political faith in the expert as a discerning judge capable of neutral decisions and, on the other hand, recognition of the expert as, simply, a person whose perceptions were by definition fallible. To manage this seeming contradiction, declarative bodies were made up of multiple experts, that is multiple subjectivities, and these multiple experts had to reach decisions together. Rather than the view from nowhere or the view from one particular perspective, this version of objectivity was imagined as a view from everywhere, which provided a distinctive form of 'bureaucratic objectivity'. ${ }^{19}$ With multiple experts, the unsavoury appearance of decisions by a single authority could be warded off. The 'givenness' and veracity of a judgment appeared to be true, not according to one expert, but to many. ${ }^{20}$

The implication was that individual members were given no legal authority to make a decision. Instead, individual members were empowered to the extent that they could act as one body, for example, to make a decision as a panel rather than as an aggregate of individual panellists. Declarative bodies came to have authority, and therefore to have an effect in the world, only to the extent that multiple, fallible individuals could act as one.

The practical challenge, then, was for multiple experts to reach an agreement, despite coming from different fields and a variety of backgrounds. Multiple individual experts had to reach a consensus, and consensus building required persuasion. ${ }^{21}$ The fact that declarative bodies and specifically 'funding panels' operate through persuasion raises questions about inequalities within funding panels: which types of experts and forms of argument are most authoritative in their deliberations behind closed doors? The practical challenge of reaching a consensus is especially daunting because the agreement that multiple experts must reach is often about qualitative concepts - novelty, risk, 
merit - and specifically, about how abstract concepts should be rendered in concrete cases. Different experts, especially those trained in different fields, regard different attributes of a practical case-at-hand as evidence of a given qualitative category. As a result, the process of evaluating a case within a declarative body involves deciding whose arguments for why a case fits a category (or not) is most persuasive: for example, whether a grant proposal that includes many questions is a sign of 'originality'.

Declarative bodies have developed a number of strategies to standardize individual expert judgments and create 'the panel's' decision. Funding organizations, for example, have often used scales and other systems of ranking and rating, which serve the purpose of turning qualitative evaluations into shared metrics in quantitative form. Nonetheless, people have used these tools, which are intended to make qualitative judgments commensurable, in very different ways. ${ }^{22}$

First, individuals have had different ideas and practices about how to rate and rank. Can more than one candidate receive the same score? Do all of the ranks have to be used? Are fractions allowed or only whole numbers? What formula should be used to turn the different numbers people assigned to a given individual into one, collective number? Likewise, members of funding panels face the tricky task of deciding the relative weight of different criteria of evaluation, such as 'quality' relative to 'diversity'. ${ }^{23}$ As a result, one study of the National Science Foundation (NSF) in the USA in the I980s concluded that 'the fate of a particular grant application is roughly half determined by the characteristics of the proposal and the principal investigator, and about half by apparently random elements which might be characterized as the "luck of the reviewer draw"'. This form of luck, or misfortune, expressed that objective reviewers could be objective in different ways. 'Some of the observed differences among scores given to the same proposal by different reviewers is undoubtedly an artefact of what anthropologists refer to as intersubjectivity,' the authors reported. 'That is, there may be two reviewers who translate their substantively identical opinions differently'. ${ }^{24}$

Second, experts give different meanings to qualitative concepts that organizations, including funding agencies, set as criteria of evaluation. Experts with different training, life experiences and sensibilities have competing ideas about what concepts, such as 'originality', 
'significance', 'feasibility', 'excellence', 'quality' or 'risk', mean and what they look like in specific cases. ${ }^{25}$ The study of NSF funding panels found that 'the great bulk of reviewer disagreement observed is probably a result of real and legitimate differences of opinion among experts about what good science is or should be.' The result was a tremendous discrepancy in reviewers' assessments, which held for the natural sciences as well as the social sciences. ${ }^{26}$ In an influential ethnographic study of elite national interdisciplinary funding panels in the USA, sociologist Michèle Lamont interviewed panel members and observed panels while the members collectively made decisions about fellowship application. Lamont similarly found wide variation in reviewers' evaluations of the same application because of individuals' different conceptions of qualitative criteria.

Lamont's work shows how the ideal vision of declarative bodies unravelled because of the tinkering required to align the practical requirement of group consensus with individual experts' different embodied sensibilities about the meaning of abstract review criteria. Lamont observed that 'the language of excellence presumes a neat hierarchy from the best to the worst proposals' and yet by virtue of the conditions of bureaucratic arrangement 'panelists adopt a pragmatic approach to evaluation'. The specific condition that drove panellists' pragmatism (over idealism) and that, I argue, characterizes declarative bodies, was the necessity for multiple people to reach a consensus. Only the panel as a collective body is authorized to make a decision, not an aggregate of individuals. Lamont observes the importance of this condition. 'They need to reach a consensus about a certain number of proposals by a predetermined time, a practical concern that shapes what they do as well as how they understand the fairness of the process'. Declarative bodies have had large consequences for individual careers and the content of knowledge despite the idiosyncratic judgements and make-shift practices their members must develop in everyday work. 'Evaluators are often aware of the inconsistencies imposed by the conditions under which they carry out their task,' Lamont writes. ${ }^{27}$

No doubt, in the three decades since the study of the NSF by Cole et al, funding organizations have changed their practices in response to empirical evidence of the patterned biases that their reviews produce and how these unjust patterns in funding outcomes structurally reproduced exclusions in research communities more broadly. Nonetheless, 
consequential changes require firm shifts in the structure of decisionmaking processes, not only individuals' good intentions with a new alertness to the problems. Indeed, thirty years on, structural inequalities persist in research communities and, as a result, in the foundational ideas about how the natural world works. These inequalities are the effect, in part, of funding panels' decision-making methods. They are, I argue, endemic to declarative bodies working within and on scientific communities. ${ }^{28}$

\section{Truth: The World-Making Power of Declarative Acts}

Declarative bodies have persisted because they have appeared to be effective in identifying what seem to be pre-existing truths: that a protocol was ethical; a college applicant was promising; a researcher was talented. Yet declarative bodies do not recognize pre-existing traits and truths about protocols, applicants or candidates. Rather, the decisions of declarative bodies (their speech acts) in a given moment create these objects. In turn, their speech acts create a future reality that validates their present decision. Declarative bodies are not betting on the future. They are creating the future through their declarations.

There are two reasons for this surprising phenomenon. First, the concepts funding panels use to make judgements (talent, worth, promise) ${ }^{29}$ come to be defined in terms of the concrete cases that they regard as instantiation of the concept. The qualitative criteria that a given group has used to make judgements (merit, morality, safety) in the practical, local space of deliberation and discussion come to mean what the group has determined bears those qualities in the world. This recursive loop between category and case, through which they (re)define each other in terms of each other, is akin to the phenomenon that philosopher Ian Hacking calls dynamic nominalism. Hacking coined this phrase to refer to how diagnostic categories define and therefore invent individuals as a particular type, and in doing so, those flesh-and-blooded people are taken to be examples of what the abstract categories mean - according to experts and often according to themselves - in turn tweaking the concepts through the ways that they fit into them.

Second, the decisions of declarative bodies are nested in time. In the case of funding panels, the studies and researchers who are deemed 
successful in a given moment become disproportionately successful in the future, not because of material advantages from a grant, but because funding panels' decisions alter the objects about which they are deciding. Studies and researchers have new qualities, that is, a reputation, which comes with status advantage. Funding panels conventionally require that researchers share information about prior grant success by asking for researchers' CVs as part of the funding application. Panellists read CVs, in part, to be told whether researchers are already defined as meritorious, rather than to decide independently for themselves..$^{30}$

In 20I8, a set of scholars tested the long-term effects on researchers' careers of early success in a grant competition. The authors designed the study to compare researchers whose projects were judged to be the nearly identical in quality by the standards of the review panel, and yet one set of researchers was awarded the grant and the other set had its grant requests declined. ${ }^{31}$ The authors found that funding panels take past success in a grant competition as a marker of talent, which meant that a different, past funding panel's decision to give a grant to one, rather than another, researcher of equal talent when judged independent of past grant success dictated the researcher's prospects in subsequent grant competitions and future career success. In the decade following the grant competition, the authors found that 'the lowest rank winners in the early competition accumulated more than twice as much grant money as the highest-ranked nonwinners'.$^{32}$ How did the authors know this disparity was not only due to material advantage from the early grant, such as money to build a lab or employ staff? Their study showed that there was no measurable difference in the scientific output (for example, number of publications) of applicants just above and just below the funding threshold. Yet in terms of overall career, the prospects for being awarded full professorship were $47 \%$ higher for the lowest ranked winners compared to the highest ranked non-winners. Regardless of demonstrated talent, funding panels in their everyday work of judgement and consensus-building based their collective decisions on reputation. Here is the surprising and politically important point: the decisions of funding panels that are evaluating applicants at a future time will align their decisions with those of funding panels making decisions in the past, not because an essential trait of the researcher or application, but rather because earlier panels created a new object, such as a quality research or meritorious study. 
As a result, the decisions of declarative bodies have a compounding effect over time for symbolic, not only material, reasons. Sociologist Robert Merton coined the phrase 'The Matthew Effect' to refer to the phenomenon in which scholar and scientists who have one success will disproportionately accrue additional successes compared to their peers, again not because their work is of superior quality, but because one success becomes an indicator for later evaluators that the person has talent, worth, originality or other meritorious qualities used in evaluations. The Matthew Effect is a theory of cumulative advantage and, as declarative bodies, funding panels create unusually strong compounding consequences. ${ }^{33}$ The authors of the 2018 comparative study explained that '[i]n contrast to scientists judging the quality of research papers, reviewers of grants, especially personal grants, are often explicitly tasked with evaluating the ability and promise of the applicant, using past achievements as criteria'. For reviewers, 'past successes aid quality assessment under uncertainty'. The long-term consequence is that 'the award competition not only produces an enduring rift in funding success, but also has a lasting impact on winners' and nonwinners' position in the academic hierarchy'. This outcome was a product of the illocutionary force of declarative bodies and is contrary to democratic notions of meritocracy.

The Matthew Effect points out the contradiction in the rhetoric and the practice of seemingly merit-based decision making in and about science. Ideally, the application that is successful would be evaluated in its own terms and in its own time. Yet in review panels, experts are more likely to award a grant or prize to researchers who have had successes in the past, even when experts regard the applications as having equal merit. It is the opposite of a share-the-wealth sensibility or commitment to the just distribution of resources across a field.

Further, according to the 2018 comparative study, evaluations and funding successes involve informal criteria, which reproduce implicit discrimination against underrepresented groups based on race and gender. As a solution, the authors of the 2018 study propose that funding panels should not be allowed to see applicants' past funding records, which is now a standard piece of data requested in grant competitions and provided on applicants' CVs. Still, declarative bodies use practices of judgement that work against people who are members of demographic groups that are already excluded and underrepresented in 
the sciences. Declarative bodies' practices of judgment set in motion the Matthew Effect, which then multiplies relative disadvantage over time. For example, ethics review panels tended to review more negatively proposals from scientists or scholars who did not share the dominant language of the review panel. If the panel worked in English and English was the first language of most panellists, they tended to judge more harshly applicants whose first language was not English. Their judgment did not reflect an assessment of the applicant's plan for the ethical protection of research participants. Instead it reflected reviewers' discomfort with unfamiliar phrasings or accents in speech, which they believed revealed that a researcher did not have English as a first language. They used this reading of the protocol more broadly as an indicator of the scientist's abilities to express herself and therefore to be an effective researcher, which then affected the scientist's future applications. ${ }^{34}$

Funding panels may be uniquely influential in some ways, but the reason for that influence, historically and in everyday practice, is common to all declarative bodies. By seeing the funding panel as a particular type of actor, namely as a declarative body, it becomes possible to conceptualize them as social actors and to appreciate the extent of their world-making effects.

\section{Conclusion}

Declarative bodies, such as funding panels, are not fortune tellers. They are fortune makers. They have immense effect both on the content of scientific knowledge and on scientists' careers. Modern scientists and scientific institutions have typically obeyed the authority of declarative bodies because of the symbolic and material resources at stake, whether grant money, article publication, career advancement or project approval. Consequently, declarative bodies have actively altered the process of knowledge making, the contours of scientific communities and the products of knowledge themselves.

By the twenty-first century, it can be hard to imagine other acceptable methods of making decisions in science, despite growing worries about the unintended, unjust outcomes that they produce across domains, from ethics review, to journal refereeing, to funding review. 
Often, proposed solutions urge that institutions and individuals 'correct' biases among members of declarative bodies. Yet the concept of declarative bodies suggests that even when funding panels and other groups are working optimally, the very method of decision making generates outcomes that are contrary to their own aspirations, such as making meritocratic decisions. A twenty-first century solution may be not (only) to reform individual decision makers, but rather to imagine new ways of making decisions, of declaring new futures and of bringing other worlds into being.

\section{Notes}

I I am grateful to Noortje Jacobs and Pieter Huistra for their feedback on earlier drafts of this article.

2 Noortje Jacobs, 'Ethics by Committee: Governing Human Experimentation in the Netherlands, I945-2000', unpublished PhD dissertation, Maastricht University, 20 I 8; Laura Stark, Behind Closed Doors: IRBs and the Making of Ethical Research (Chicago, 20I2); Adam Hedgecoe, 'Research Ethics Review and the Sociological Research Relationship,' Sociology 42:5 (2008) 873-86; Stefan Sperling, Reasons of Conscience (Chicago, 20I3); James Benjamin Hurlbut, 'Experiments in Democracy: The Science, Politics and Ethics of Human Embryo Research in the United States, I978-2007', unpublished $\mathrm{PhD}$ dissertation, Harvard University, 20Io; John H. Evans, Playing God?: Human Genetic Engineering and The Rationalization of Public Bioethical Debate (Chicago, 2002); Melinda Baldwin, 'Scientific Autonomy, Public Accountability, and the Rise of "Peer Review" in the Cold War United States,' Isis I09:3 (2018) 538-58.

3 Based on a long-term study of several national elite US funding panels, sociologist Michèle Lamont characterizes members of funding panels as "highly regarded experts known for their good "people skills" and sound judgments. They have agreed to serve on grant peer review panels for a host of reasons having to do with influence, curiosity, or pleasure. Some say that they are "tremendously delighted" to spend a day or two witnessing brilliant minds at work. Others serve on panels to participate in a context where they can be appreciated, that is, where they can sustain and ideally, enhance - their identities as highly respected experts whose opinions matter'. Anthropologist Donald Brenneis describes members of funding panels in similar terms, drawing from his long-term ethnographic 
study and personal service on review panels for the NIH, NSF, NEH and NRC in the USA. Michèle Lamont, How Professors Think: Inside the Curious World of Academic Judgment (Harvard, 20I0); Donald Brenneis, 'Discourse and Discipline at the National Research Council: A Bureaucratic Bildungsroman,' Cultural Anthropology 9: I (I994) 23-36.

4 J. L. Austin, How to Do Things with Words, J. O. Urmson and Marina Sbisà (eds) (Harvard, 1975). One important specification, is that words have to be uttered by an individual who is understood to have this world-making power within a specific context. Illocutionary force does not pertain only to the words, but to the combination of words, person and context. For an elaboration of the speech-act theory in terms of declarative bodies, see Laura Stark 'Declarative Bodies: Bureaucracy, Ethics and Knowledge in the Making' Daniel Kleinman and Kelly Moore (eds) Routledge Handbook of Science, Technology and Society (Routledge, 20I4) 437-55.

5 Wendy Nelson Espeland and Michael Sauder, 'Rankings and Reactivity: How Public Measures Recreate Social Worlds,' American Journal of Sociology I I3: I (2007) I-40; Justin B. Richland, 'Jurisdiction: Grounding Law in Language,' Annual Review of Anthropology 42:I (2013) 209-26.

6 Lorraine J. Daston and Peter Galison, Objectivity (Zone Books, 20Io); Theodore M. Porter, Trust in Numbers: The Pursuit of Objectivity in Science and Public Life (Princeton, 1995); Paul Lucier, 'The Professional and the Scientist in Nineteenth-Century America,' Isis I00:4 (2009) 699-732.

7 Mark Solovey and Hamilton Cravens, Cold War Social Science: Knowledge Production, Liberal Democracy, and Human Nature (Springer, 2012); Thomas Nagel, The View from Nowhere (Oxford, I986).

8 Steven Shapin, Never Pure: Historical Studies of Science as If It Was Produced by People with Bodies, Situated in Time, Space, Culture, and Society, and Struggling for Credibility and Authority (Baltimore, 2010); Donna Haraway, 'Situated Knowledges: The Science Question in Feminism and the Privilege of Partial Perspective,' Feminist Studies I4:3 (1988) 575-99; Laurent Thévenot, 'Postscript to the Special Issue: Governing Life by Standards: A View from Engagements,' Social Studies of Science 39:5 (2009) 793-8I3.

9 Wendy Nelson Espeland, 'Bureaucratizing Democracy, Democratizing Bureaucracy,' Law \& Social Inquiry 25:4 (2000) I077-I09; Daryl E. Chubin, Peerless Science: Peer Review and U.S. Science Policy (Albany, I990).

Io Steven Shapin and Simon Schaffer, Leviathan and the Air-Pump: Hobbes, Boyle, and the Experimental Life, Reprint (Princeton, 20I I); Ken Alder, 
The Measure of All Things: The Seven-Year Odyssey and Hidden Error That Transformed the World (New York, 2003); Jill S. Quadagno, One Nation, Uninsured: Why the U.S. Has No National Health Insurance (Oxford, 2006); Paul Starr, The Social Transformation of American Medicine (New York, I982); Ellen Herman, Kinship by Design: A History of Adoption in the Modern United States (Chicago, 2008); Brian Steensland, The Failed Welfare Revolution: America's Struggle over Guaranteed Income Policy (Princeton, 2008).

I I Solovey and Cravens, Cold War Social Science.

I 2 Mark Solovey, Shaky Foundations the Politics-Patronage-Social Science Nexus in Cold War America (New Brunswick NJ, 20I3); Daniel Kevles, 'The National Science Foundation and the Debate over Postwar Research Policy, I942-I945: A Political Interpretation of "Science - The Endless Frontier," Isis 68:I (I977) 5; J. Merton England, A Patron for Pure Science: The National Science Foundation's Formative Years, I945-57 (National Science Foundation, I982).

I3 Daston and Galison, Objectivity.

I4 Elizabeth A. Boyd, 'Bureaucratic Authority in the "Company of Equals": The Interactional Management of Medical Peer Review,'American Sociological Review 63:2 (1998): 200-24; Monika Krause, The Good Project: Humanitarian Relief NGOs and the Fragmentation of Reason (Chicago, 20I4).

I 5 Charles H. Koch, Administrative Law (Aspen, 2002).

I6 Cole et al estimate that there are only one or two dozen people who are qualified to evaluate any given funding proposal in the sciences because of the specificity of the fields. See also Stephen Turner, 'What is the Problem with Experts?', Social Studies of Science 3 I: I (200 I): I23-49; S. Cole, J. R. Cole, and G. A. Simon, 'Chance and Consensus in Peer Review,' Science 2 I 4:4523 (I98I) 88I-86.

I7 Turner, 'What is the Problem with Experts?'

I 8 Daston and Galison, Objectivity. The appeal of objectivity as an 'epistemic virtue' stemmed from the Kantian distinction between noumena and phenomena. The history of modern science can be read as a story about historical actors' efforts to create the appearance that they, in all their presumed fallibility, affected the knowledge made. As a refinement and query into the problems with extending this argument too broadly, see Laura Stark and Nancy D. Campbell, 'The Ineffable: A Framework for the Study of Methods through the Case of Mid-Century Mind-Brain Sciences,' Social Studies of Science 48:6 (2018) 789-820. 
I9 In addition to the important literature on bureaucratic objectivity, my understanding of 'bureaucratic objectivity' is indebted to, though distinct from, other scholars' work on regulatory and pragmatic objectivity. The requirement that groups of experts make decisions collectively is more akin to Sandra Harding's ideal of scientific observations using 'strong objectivity'. Alberto Cambrosio et al., 'Biomedical Conventions and Regulatory Objectivity: A Few Introductory Remarks,' Social Studies of Science 39:5 (2009): 65I-64; Tiago Moreira, Carl May, and John Bond, 'Regulatory Objectivity in Action Mild Cognitive Impairment and the Collective Production of Uncertainty,' Social Studies of Science 39:5 (2009): 665-90; Linda F. Hogle, 'Pragmatic Objectivity and the Standardization of Engineered Tissues,' Social Studies of Science 39:5 (2009) 717-42; Sandra Harding, Objectivity and Diversity: Another Logic of Scientific Research (Chicago, 2015); Anna Weichselbraun, 'Constituting the International Nuclear Order: Bureaucratic Objectivity at the IAEA' (Chicago, 20I6).

20 Many but not all declarative bodies use peer review and instead adopt other forms of collective decision-making as seen in college admissions committees or humanitarian aid organizations. Thus, declarative bodies are not synonymous with peer review. Nonetheless the virtue of impersonal decision-making about science by scientists relates to this long history of peer review. For example, the National Institutes of Health in the USA, awarded funding through contracts until the I950s. The use of peer review was one method through which post-war funding bodies worked to obscure the local, intimate contexts through which experts, administrators and applicants established trust - in each other, in working conditions and thus in scientific findings - in order to create the appearance of impersonal and therefore democratic knowledge. It marked a shift in how funders made decisions and, as a result, the standards by which they judged scientific quality. Richard Mandel, A Half Century of Peer Review, 1946-1996 (Bethesda, MD I996); Chubin, Peerless Science; Krause, The Good Project; Michell Stevens, Creating a Class: College Admissions and the Education of Elites (Harvard, 2009); Baldwin, 'Scientific Autonomy'; Alex Csiszar, 'Peer Review: Troubled from the Start,' Nature 532:7599 (2016) 306-8.

2I Stark, Behind Closed Doors, 2 I-40.

22 Owen Whooley, 'Measuring Mental Disorders: The Failed Commensuration Project of DSM-5,' Social Science \& Medicine I66 (2016) 33-40; Wendy Nelson Espeland and Mitchell L. Stevens, 'Commensuration as a Social Process,' Annual Review of Sociology 24:I (I998) 313-43; John H. 
Evans, 'Max Weber Meets the Belmont Report: Toward a Sociological Interpretation of Principlism,' James F. Childress, Eric M. Meslin and Harold T. Shapiro (eds), Belmont Revisited: Ethical Principles for Research with Human Subjects (Georgetown, 2005) 228-43.

23 Lamont, How Professors Think.

24 Cole, Cole and Simon, 'Chance and Consensus in Peer Review.'

25 Lamont; Joshua Guetzkow, Michèle Lamont, and Gregoire Mallard, 'What Is Originality in the Humanities and the Social Sciences?,' American Sociological Review 69:2 (2004) I90-2 I 2.

26 Cole, Cole and Simon, 'Chance and Consensus in Peer Review.'

27 Lamont, How Professors Think, 6.

28 Barry Bozeman and Paul Hirsch, 'Science Ethics as a Bureaucratic Problem: IRBs, Rules, and Failures of Control,' Policy Sciences 38:4 (2005) 269-9I; Laura Stark, 'Reading Trust Between the Lines: "Housekeeping Work" and Inequality in Human-subjects Review', Cambridge Quarterly of Human Subjects Protections 22: 4 (20I3) 39I-9; Brenneis, 'Discourse and Discipline'.

29 Lamont, How Professors Think.

30 Baldwin, 'Scientific Autonomy', 564; Wolfgang Kaltenbrunner and Sarah de Rijcke, 'Filling in the Gaps: The Interpretation of Curricula Vitae in Peer Review', Social Studies of Science (2019) (https://doi. org/Io. I I77/03063I 27I9864I64).

3I Specifically, they compared recent PhDs in the sciences who were just above and just below the threshold for receiving a grant. This design meant that the funding panel regarded their applications as nearly identical in quality, which allowed the authors to control for the quality of projects and scholars by panels' own standards. They isolated 'the effects of recent PhDs winning an early career grant by comparing the subsequent funding success of nonwinners with evaluation scores just below the threshold to winners with scores just above it' (page 4888). Thijs Bol, Mathijs de Vaan and Arnout van de Rijt, 'The Matthew Effect in Science Funding,' Proceedings of the National Academy of Sciences (PNAS, 2018).

32 Ibid.

33 In the 20 I 8 study described above, the authors described and operationalized the Matthew Effect as the 'self-reinforcing dynamic in academic stratification borne out of the tendency for a scientist's past success to positively affect success in the future. The theory is that if only one of two equally talented young scholars is given an award, the award-winning scholar will go on to 
have the more successful career. This happens because the winner enjoys resource and status advantages over the nonwinner' (page 4887). Bol, De Vaan and Van de Rijt, 'The Matthew Effect in Science Funding'; Robert K. Merton, 'The Matthew Effect in Science,' Science I59:38 Io ( I968) 56-63. 34 Laura Stark, 'The Language of Ethics: How Ethics Review Creates Inequalities for Language Minorities in Research', Will C. van den Hoonaard and Ann Hamilton (eds), The Ethics Rupture: Exploring Alternatives to Formal Research-Ethics Review (Toronto, 20I6) 9I-I05.

\section{About the Author}

Laura Stark is an associate professor at Vanderbilt University's Center for Medicine, Health, and Society, and Associate Editor of the journal History \& Theory. She is the author of Behind Closed Doors: IRBs and the Making of Ethical Research (2012), and is completing a new book project on the lives of 'normal control' research subjects at the National Institutes of Health in the USA. Her articles and book chapters explore medicine, morality and the modern state in a global frame.

website: www.laura-stark.com

E-mail: laura.stark@vanderbilt.edu 